\title{
Deciphering Role of Amino Acids for the Stability of Staphylococcus aureus Lipase (SAL3)
}

\author{
Saravanan PARAMESWARAN, Alpana Ankush THROAT, Sanjukta PATRA* \\ (Department of Biotechnology, Indian Institute of Technology Guwahati, Assam 781039, India)
}

\section{Erratum to Interdiscip Sci Comput Life Sci (2010) 2: 271-279}

DOI: $10.1007 / \mathrm{s} 12539-010-0029-6$

The original version of this article unfortunately contained a mistake. The spelling of the first author's name was incorrect in the paper version and the HTML version of this article. The correct spelling is Saravanan PARAMESWARAN.

The online version of the original article can be found at http://dx.doi.org/10.1007/s12539-010-0029-6.

\footnotetext{
${ }^{*}$ Corresponding author.

E-mail: sanjukta@iitg.ernet.in
} 